\title{
Sınıf Öğretmenlerinin Beden Eğitimi ve Oyun Dersi Öğretimindeki Güven Seviyelerinin Değerlendirilmesi
}

\author{
Evaluation of Self-Confidence Level of Classroom Teachers in Teaching Physical \\ Education and Game Course
}

\author{
${ }^{1}$ Nilgün ULU \\ ${ }^{2}$ Tuba YAZICI \\ ${ }^{2}$ Irmak HÜRMERİÇ ALTUNSÖZ
}

\begin{abstract}
${ }^{1}$ Nesibe Aydın Okulları
${ }^{2}$ Orta Doğu Teknik Üniversitesi, Beden Eğitimi ve Spor Bölümü
\end{abstract}

\section{Yazışma Adresi \\ Corresponding Address:}

Doç. Dr. Irmak Hürmeriç Altunsöz

ORCID: 0000-0002-8570-196X

ODTÜ Beden Eğitimi ve Spor Bölümü

E-posta: hurmeric@metu.edu.tr

\section{öz}

Bu çalışmanın temel amacı sınıf öğretmenlerinin beden eğitimi ve oyun dersi öğretimi sırasındaki güven seviyelerinin araştırılmasıdır. Buna ek olarak; cinsiyet, okutulan sınıf ve hizmet yılı gibi faktörlerin öğretmenlerin güven seviyesine etkisi olup olmadığı araştırılmıştır. Çalışmaya Ankara'nın Çankaya ilçesinde görev yapan 320 (147 Kadın ve 173 Erkek) sınıf öğretmeni gönüllü olarak katılmıştır. Sınıf öğretmenlerinin beden eğitimi ve oyun dersi öğretimi sırasındaki güven seviyelerini ölçmek için Spittle, Watt ve Spittle (2011) tarafından geliştirilen ve Türkçeye adapte edilen $6^{\prime}$ । likert yapıya sahip, 2 alt boyutlu (yönetim ve planlama becerileri, spor becerileri öğretimi) kendine güven ölçeği kullanılmıştır. Sınıf öğretmenlerin ders öğretimi sırasındaki kendilerine güven seviyesi orta düzeyde bulunmuştur $(X=4.00, S S=0.95)$. Öğretmenlerin beden eğitimi ve oyun dersindeki yönetim ve planlama becerileri konusundaki güven seviyeleri $(X=4.24, S S=0.93)$, spor becerileri öğretimi $(X=3.23, S S=1.29)$ konusundaki güven seviyesinden daha yüksek çıkmıştır. Kadın ve erkek sınıf öğretmenlerinin beden eğitimi ve oyun dersindeki güven seviyeleri arasında anlamlı bir fark çıkmamıştır. Öğretmenlerin hizmet yılı (Wilks' $\lambda=.969, F(6,630)=1.65, p>.05$ ) ve okuttukları sınıf düzeyi (Wilks' $\lambda=.987, F(6,632)=.682, p>.05)$ ile bu dersin öğretimi sırasındaki kendine güven seviyeleri arasında da anlamlı bir fark bulunmamıştır. Farklı branşlara yönelik spor öğretim becerileri konusunda sınıf öğretmenlerine hizmet içi eğitimlerin verilmesi, yönetim ve planlama konusunda öğretmenlere alan uzmanları yardımı ile destek sağlanması dersin etkinliğinin artırılması için yararlı olacaktır.

Anahtar Kelimeler: Sınıf öğretmenleri, Beden eğitimi ve oyun dersi, Özgüven, Öğretim becerileri

\section{ABSTRACT}

The main purpose of this study was to examine the self-confidence level of classroom teachers in teaching physical education and game course. Besides, whether factors such as gender, class and year of service affect the self-confidence level of teachers was investigated. This study was conducted at Çankaya District, and 320 teachers (147 female and 173 male) have voluntarily participated in this study. The self-confidence scale developed by Spittle, Watt, and Spittle (2011) was used to measure the confidence levels of the classroom teachers in teaching the physical education and game course. The self-confidence scale, which is adapted to Turkish, has a 6-point Likert structure and consists of 2 sub-dimensions (management and planning skills, sports skills). Findings revealed that classroom teachers had a low level of selfconfidence while teaching physical education and game course $(M=4.00, S D=.95)$. Teachers' confidence level in management and planning skills ( $M=4.24, S D=.93)$ was higher than teaching sports skills $(M=3.23, S D=1.29)$. Besides, there was no significant difference between the confidence level of male and female classroom teachers. It was also found that there was no significant difference between experience year and teachers' confidence level (Wilks' Lambda $=.969, \mathrm{~F}(6,630)=1.65, \mathrm{p}>.05$ ), and between grade level and teachers' self-confidence level (Wilks' Lambda $=.987, \mathrm{~F}(6$, $632)=.682, p>.05)$. Providing in-service training to classroom teachers on teaching sports skills in various branches and providing support to teachers with the help of field experts in management and planning will be beneficial to increase the effectiveness of the course.

Key Words: Classroom teachers, Physical education and game course, Selfconfidence, Teaching skills 


\section{GíRiş}

Özgüven motivasyonumuzu, duygularımızı ve davranışlarımızı etkileyenen önemli bir etken olarak tanımlanmaktadır (Bandura, 1986). Buna ek olarak, özgüven, kendi bilgi ve becerilerimizi değerlendirerek, belirli bir hedefi gerçekleştirip gerçekleştiremeyeceğimize karar vermemizi sağlayan mekanizmalar içermektedir (National Research Council, 1994). Özgüvenin farklı kaynaklarda tanımları incelediğinde ise "kendine güvenme işi”, "kendi özellikleri konusunda olumlu ya da olumsuz yorum" ve "kendi hakkında farkındalık" gibi tanımları olduğu görülmektedir (Türk Dil Kurumu, Vikipedi vs). Bu bağlamda özgüven, mesleki anlamda uzmanı olduğumuz alanda performansımızı etkiyelen unsurlardan biri olarak da tanımlanabilir.

Öğretmenlerin özgüveni alanyazında sıklıkla araştırılan konulardan biridir, çünkü öğretmenlerin özgüveni öğrenci başarısını ve öğrenci davranışlarını önemli ölçüde etkilemektedir (Ashton, 1984; Tschannen-Moran, Hoy ve Hoy, 1998; Weimer, 2012). Makwana'ya (2013) göre öğretmenlerin özgüveni öğretme becerilerindeki gelişim ile doğru orantılıdır. Özgüveni yüksek olan öğretmenlerin motivasyonlarının yüksek olduğu, ders içeriklerinin hazırlanmasında ve ders işleme yöntemlerinde daha etkili oldukları bilinmektedir (Cotton, 2013). Buna ek olarak, bu öğretmenlerin branşlarına özgü öğretim tekniklerinde yaratıcı oldukları, öğrencileri soru sormaya ve yaratıcılıklarını kullanmaya teşvik ettikleri ve problemli davranışları kontrol etmede daha etkili oldukları belirtilmektedir (Cotton, 2013). Özgüveni düşük olan öğretmenlerin ise dersteki performanlarının pekiyi olmadığı (Weimer, 2012) ve sınıf içinde beklenmeyen durumlar ile baş edemedikleri görülmektedir (Jones ve Mason, 2012).

Öğretmenlerin kendi branşları dışındaki derslere girmek zorunda kaldıkları zaman, ders işleyişi konusunda özgüvenlerinin düşük olduğunu ve dolayısıyla da bu durumun dersteki performanslarını olumsuz yönde etkilediğini gösteren çalışmalar bulunmaktadır (Morgan ve Bourke, 2008; Watt, 2000). Öğretmenlerin kendi alanı olmayan derslere girme nedenleri okuldaki öğretmen sayısı azlı̆̆ı, branş öğretmenin olmaması veya farklı okul politikaları olarak sıralanabilir. Özellikle, beden eğitimi ve spor dersine farklı branş öğretmenlerinin girdiği ulusal ve uluslararası alanyazında görülmektedir. Örneğin; Birleşmiş Milletler Eğitim, Bilim ve Kültür Örgütü'nün (UNESCO-United Nations Educational, Scientific and Cultural Organization) 2014 yılında yayımladığı "Dünya genelindeki beden eğitimi ve spor dersi” ile ilgili raporunda, ilkokullarda okutulan beden eğitimi ve spor dersine alan uzmanı olmayan öğretmenlerin (\%79) girdiği belirtilmektedir (UNESCO, 2014). Aynı raporda Almanya, Portekiz, İsveç gibi Avrupa ülkelerinde alan uzmanı olmayan (generalist teachers) öğretmenlerin beden eğitimi ve spor dersinden sorumlu oldukları görülmektedir (UNESCO, 2014). Buna paralel olarak, birçok çalışmada beden eğitimi dersine giren alan uzmanı olmayan sınıf öğretmenlerinin dersteki etkinliği tartışma konusudur (Arslan ve Altay, 2008; Bozdemir, Çimen, Kaya ve Demir, 2015; Chroinin ve O'Sullivan, 2016; Faulkner et al., 2008; Morgan ve Bourke, 2008; Petrie, 2010) ve son otuz yıldır uluslararası alanyazında sınıf öğretmenlerinin beden eğitimi ile ilgili yeterliklerini, deneyimlerini ve tutumlarını inceleyen çalışmalar mevcuttur (Petrie, 2010).

Benzer olarak ülkemizde sınıf öğretmenlerinin beden eğitimi dersine girdikleri alanyazında yapılan birçok çalışmada görülmektedir (Arslan ve Altay, 2008; Pehlivan, Dönmez ve Yaşat, 2005). Sınıf öğretmenleri 2012-2013 öğretim yılından itibaren Milli Eğitim Sisteminde yapılan değişiklik ile beden eğitimi ve spor dersinin yerini alan "oyun ve fiziki etkinlikler" dersinden sorumlu olmuşlardır. Dersin adı 2018 y1lında "beden eğitimi ve oyun" olarak değiştirilmiştir (MEB, 2018). Bu dersin genel hedefleri öğrencilere aktif ve sağlıklı bir hayat sürdürebilmeleri için temel bilgiler ve beceriler kazandırırken, olumlu davranışlar geliştirmelerini sağlamaktır (MEB, 2012). Beden eğitimi ve oyun dersi "hareket yetkinliği”" ve "aktif ve sağlıklı hayat" olmak üzere iki ana öğrenme alanından oluşmaktadır (MEB, 2018). Her ana 
öğrenme alanında 3 temel alt öğrenme alanı vardır. Bunlar hareket yetkinliği için; hareket becerileri, hareket kavramları ve ilkeleri ve hareket stratejileri ve taktikleri, aktif ve sağlıklı hayat için; düzenli fiziksel etkinlik, fiziksel etkinlik kavramları-ilkeleri ve ilgili hayat becerileri ve kültürel birikimlerimiz ve değerlerimiz olarak sıralanmaktadır (MEB, 2012 ve 2018). Bu öğrenme alanlarındaki hedeflenen kazanımlara ulaşmak için sınıf öğretmenlerinin dersi etkili bir şekilde işlemesi gerekmektedir. Fakat bu dersle ilgili sınıf öğretmenlerinin yaşadığı deneyimleri araştıran bilimsel çalışmalar incelendiğinde, sınıf öğretmenlerinin ders ile ilgili çeşitli problemlerle karşılaştıkları görülmektedir.

Bu çalışmalar 2014-2017 yılları arasında Ankara, Amasya, Elazı̆̆g, Konya, Muş ve Ordu gibi çeşitli illerde gerçekleştirilmiştir (Bayat, Kaymak ve Balc1, 2016; Can-Ceylan ve Dalaman, 2017; Dağdelen ve Kösterelioğlu, 2015; Kazu ve Aslan, 2014; Tel, Bozkurt ve Celayir, 2016; Şentürk, Yılmaz ve Gönener, 2015; Yıldız ve Güven, 2014). Farklı illerde yapılan çalışmalarda sınıf öğretmenlerinin programı anlayamama veya dersi işleyememe gibi benzer sorunlar yaşadığı ortaya çıkmıştır. Buna ek olarak; bu çalışmalarda daha çok öğretmen görüşlerine, deneyimlerine ve beklentilerine yer verilmiştir. Ancak, sınıf öğretmenlerinin ders öğretimi sırasındaki güven seviyelerini araştıran herhangi bir çalışmaya ulusal alanyazında rastlanılmamıştır. Sınıf öğretmelerinin öğretim performanslarını ve öğretim becerilerini kendilerine duydukları özgüvenin etkilediği bilinmektedir (Sumantri ve Wardhani, 2018).

Bu sebeple, dersin öğretim kısmında yaşanan sorunların çözülebilmesi için öğretmenlerin hangi alanlarda kendilerine güven duyup duymadıklarının belirlenmesi; öğretmen yeterliklerinin geliştirilmesi, hizmet içi ve hizmet sonrası öğretmen ihtiyaçlarının belirlenmesinde önemli rol oynamaktadır. Bununla birlikte, öğretmen ihtiyaçlarının belirlenmesi bu dersin kalitesinin artırılması ve öğretmenlerin lisans eğitimi sırasındaki aldıkları eğitiminin içeriğinin gözden geçirilmesi için de yol gösterici olacaktır. Bundan yola çıkılarak; bu çalışmanın temel amacı sınıf öğretmenlerinin beden eğitimi ve oyun dersi öğretimi sırasındaki güven seviyelerinin araştırılmasıdır. Buna ek olarak; cinsiyet, okutulan sınıf ve hizmet yılı gibi faktörlerin öğretmenlerin bu dersteki kendilerine güven seviyesine etkisi olup olmadığı araştırılmıştır.

\section{YÖNTEM}

Örneklem: Bu çalışma, Ankara'nın Çankaya ilçesinde uygun örnekleme yöntemi kullanılarak gerçekleştirilmiştir. Milli Eğitim Bakanlı̆̆ı'ndan alınan okul listeleri kullanılarak 32 devlet okulunda görev yapan toplam 782 sınıf öğretmeni belirlenmiştir. Bu öğretmenlerden 320'si (147 Kadın ve 173 Erkek) çalışmaya gönüllü olarak katılmıştır. Tablo 1'de sınıf öğretmenlerin genel demografik bilgileri sunulmaktadır.

Tablo 1. Sınıf öğretmenlerinin demografik özellikleri

\begin{tabular}{lll}
\hline Sınıf Öğretmenleri & Sayı & \% \\
\hline Cinsiyet & & \\
\hline Kadın & 147 & 46 \\
Erkek & 173 & 54 \\
\hline Eğitim Durumu & & \\
\hline Lisans & 277 & 87 \\
Yüksek Lisans & 43 & 13 \\
\hline Okutulan Sınıf & & \\
\hline 1. Sinıf & 101 & 32 \\
2. Sinıf & 66 & 21 \\
3. Sinıf & 86 & 27 \\
4. Sinıf & 67 & 21 \\
\hline
\end{tabular}




\section{Veri Toplama Araçları:}

Beden Ĕgitimi ve Oyun Dersi Öğretimindeki Kendine Güven Ölçeği: Sınıf öğretmenlerinin beden eğitimi ve oyun dersi öğretimi sırasındaki güven seviyelerini ölçmek için Spittle, Watt ve Spittle (2011) tarafından geliştirilen 6’li likert yapıya sahip ve 2 alt boyutlu kendine güven ölçeği kullanılmıştır. Bu ölçek Avustralya Sağlık, Beden Eğitimi ve Rekreasyon komitesi tarafından tanınan bir ölçektir. Ölçeğin Türkiye'de uygulanabilirliğini değerlendirmek üzere iki beden eğitimi ve spor alan uzmanından görüş alınarak ölçeğin beden eğitimi ve oyun dersi amaçları ve içeriği ile paralellik gösterdiğine karar verilmiştir. Kullanılan ölçeğin orjinali İngilizce olduğu için Türkçe’ye çevrilerek adaptasyon çalışması yapılmıştır.

Ölçek temel olarak 2 ana bölümden oluşmaktadır. Birinci bölüm yaş, cinsiyet, meslekte hizmet yılı ve eğitim seviyesi gibi genel demografik sorulardan oluşmaktadır. İkinci bölüm ise “yönetim-planlama becerileri” ve "spor becerileri öğretme” alt boyutlarını ölçen 24 sorudan oluşmaktadır. Ölçekteki alt boyutlar beden eğitimi ve oyun alt boyutları (hareket yetkinliği, aktif ve sağlıklı hayat) ile uyumludur.

Ölçekte “..... Konularında becerilerime güveniyorum” başlangıç cümlesi yer almaktadır ve "kesinlikle katılıyorum” dan "kesinlikle katılmıyorum”a doğru likert yapısı ile sorular cevaplanmaktadır. Ölçekte yer alan sorulardan örnekler şu şekildedir; "motor beceriler ve daha karmaşık hareketler öğretmede"; "net, mücadeleci ve başarılabilir öğrenme hedeflerini öğrenciler için oluşturmada" ya da "öğrenci merkezli bir öğrenim ortamı yaratıp bunu sürdürerek, fiziksel aktivite ve katılımı artırmada kendime güveniyorum.”

\section{Ölçeğin Adaptasyon Çalışması}

Dil Geçerliği: Adaptasyon çalışmasının örneklem grubunu ana çalışmada yer almayan 301 farklı (134 Kadın, 167 Erkek) sınıf öğretmeni oluşturmaktadır. Anketin Türkçeye uyarlanması için üç dil uzmanı güven ölçeğini Türkçe’ye çevirmiştir (Jones, Lee, Phillips ve Jaceldo, 2001). Daha sonra ölçeğin orjinal biçimini bilmeyen farklı üç dil uzmanı Türkçe'ye çevrilen soruları tekrar İngilizce'ye çevirmiştir. Çeviri işlemleri bittikten sonra iki beden eğitimi ve spor alan uzmanı orijinal ölçeği ve bu çevirileri kullanarak soruları anlam ve deyimsel yönden incelemiş ve Türkçe ölçek oluşturulmuştur (Beaton, Bombardier, Guillemin ve Ferraz, 2000). Daha sonra ölçek hakkında 15 sınıf öğretmeninden soruların anlaşılırlığı hakkında geri bildirim alınmıştır. Gelen öneriler ve geri bildirimler doğrultusunda ölçek son haline getirilmiştir.

Açımlayıcı Faktör Analizi: Çalışmada kullanılan ölçekteki maddelerin boyutsal yapısına ilişkin bir karar vermek için açımlayıcı faktör analizi (EFA) uygulanmıştır. Açımlayıcı faktör analizi (EFA) yapmadan önce Skewness-Kurtosis değerleri, normallik testleri (Kolmogorov-Smirnov ve Shapiro-Wilk), histogramlar ve Q-Q Plots gibi gerekli varsayımlar kontrol edilip sağlanmıştır. Çok değişkenli normallik Mardia testiyle değerlendirilmiştir. Mardia testinin sonucunun anlamlı çıkmasından dolayı muhtemel faktörleri ortaya çıkarmak için Principal Axis Factoring (PAF) ve oblimin döndürme yöntemi kullanılmıştır. Ölçeğin faktör yapısını değerlendirmek üzere korelasyon matrisi .30 ve üzeri korelasyon katsayıları göz önüne alınarak kontrol edilmiştir. Elde edilen sonuçlara göre, .30'un üzerinde olan maddeler arasında korelasyonlar vardır (Hair ve ark., 2006). Faktör yüklemelerinin sonuçları birinci faktöre ve ikinci faktöre yüklenen maddelerin bulunduğunu ancak bazı çapraz yüklü maddelerin olduğunu ortaya koymuştur. Yedi maddenin faktör yüklemeleri .10 ve .21 arasında değişmiştir. Faktör yükleme değerleri, .30'dan küçük olduğu için bu maddeler ölçekten çıkarılmıştır (Hair ve ark., 2006). 13 maddeyi içeren Faktör 1, sınıf öğretmeni yönetimi ve planlama becerileri konusunda öğretmenin güveniyle ilgili olduğu için 1. Faktör "Yönetim ve Planlama Becerileri" olarak adlandırılmıştır. Dört maddeyi içeren Faktör 2, sınıf öğretmeninin spesifik spor becerilerinin öğretilmesiyle ilgili olduğu için 2. Faktör 
"Spor Becerilerinin Öğretimi" olarak adlandırılmıştır. Ayrıca, öz değer ve scree plot sonuçları bir uyum içinde olup, ölçeğin iki faktöre sahip olduğunu desteklemiştir (Tablo 2). Açımlayıcı faktör analizi sonuçlarına göre ölçeğin 2 faktörlü (Yönetim ve Planlama Becerileri/Spor Becerileri Öğretimi) ve 17 maddeli olduğu belirlenmiştir. İki faktör yapısına sahip ölçek varyansın \%53’ünü açıklamıştır.

Tablo 2. Öz değerler, açıklanan varyans ve toplam varyans değerleri

\begin{tabular}{llll}
\hline Faktörler & Öz değerler & Açıklanan Varyans \% & Toplam \% \\
\hline $\mathbf{1}$ & 8.55 & 50.31 & 47.54 \\
$\mathbf{2}$ & 1.29 & 7.63 & 52.62 \\
\hline
\end{tabular}

Ayrıca faktör plot aşağıdaki Figür 1'de görülen ikili faktör yapısını desteklemektedir

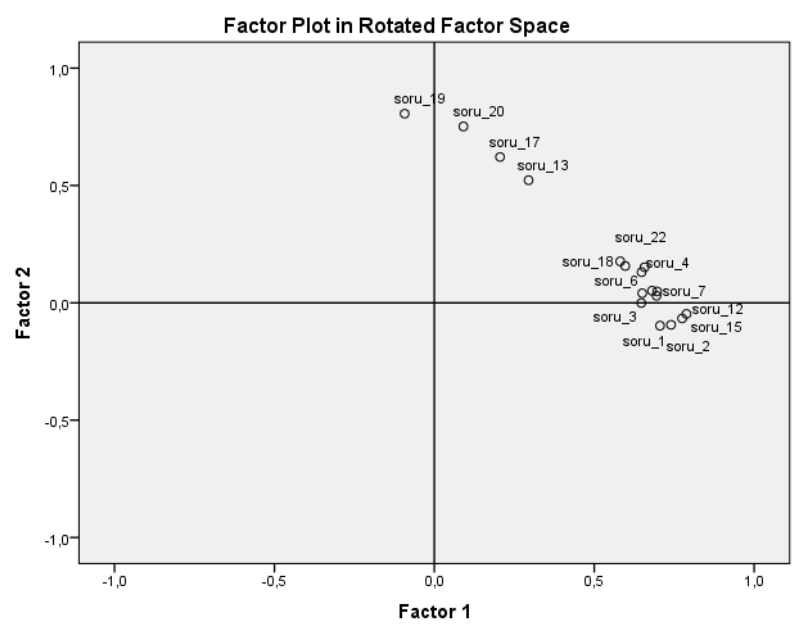

Figür 1. Faktör Plot

Doğrulayıcı Faktör Analizi: Doğrulayıcı faktör analizi ölçüm araçlarının verilerle tutarlı olup olmadığını ölçmek için sıklıkla kullanılan istatistiksel bir tekniktir (Graham, Guthrie ve Thompson, 2003). Açımlayıcı faktör analizi tarafindan faktör yapısı belirlenen ölçeğin veri ile uyumunu doğrulamak için doğrulayıcı faktör analizi yapılmıştır. Doğrulayıcı faktör analizi maximum likelihood yöntemi kullanılarak gerçekleştirilmiştir (Arbuckle, 1999). Model, açımlayıcı faktör analizi sonucunda şekillendirilmiş olan iki faktör ve on yedi maddeden oluşan modelidir. Modelin yeterliliği, beş farklı uyum indeksi kullanılarak değerlendirilmiştir: (1) model $\chi 2$, genel uygunluk ölçüsü, anlamlı olmayan $\chi^{2}$ iyi uyum gösterir; (2) $\chi 2$ /sd, iki ve üç arasında bir değerin çıkması iyi bir uyumun göstergesidir (Kline, 1998); (3) Goodness of Fit Index (GFI), 0.90'ın üzerinde olan değerler iyi bir uyum olarak kabul edilmiştir (Schumacker ve Lomax, 1996); (4) karşılaştırmalı uyum indeksi (CFI), .90 üzerindeki değerler iyi uyumun göstergesidir (Bentler, 1990); (5) RMSEA, Sıfır ve bir arasında değer alması beklenir (Browne ve Cudeck, 1993); (6) Tucker-Lewis İndeksi (TLI), 0.90'ın üzerinde olan puanlar tavsiye edilen bir uyum olarak kabul edilmiştir (Tucker ve Lewis, 1973). Bu çalışmada kullanılan ölçeğin doğrulayıcı faktör analizi sonuçlarına göre model kabul edilebilir referans aralıklarına uygundur $(\chi 2=336.44, \mathrm{df}=117$, $\chi 2 / \mathrm{df}=2.87$; GFI $=0.88, \mathrm{CFI}=0.92 ; \mathrm{RMSEA}=.076 ; \mathrm{TLI}=0.91)($ Tablo 3$)$. 
Tablo 3. Model için uyum iyiliği istatistik sonuçları $(\mathrm{n}=301)$

\begin{tabular}{llllllll}
\hline & $\chi^{2}$ & df & $\chi^{\mathbf{2}} / \mathbf{d f}$ & RMSEA & GFI & TLI & CFI \\
\hline Model & 336.44 & 117 & 2.87 & .076 & .88 & .91 & .92 \\
\hline
\end{tabular}

Note: RMSEA: Root mean Square Error of Approximation; GFI: Goodness of Fit Index; GFI: Goodness-of-Fit Index; CFI:

Comparative Fit Index

Güvenirlik: Ölçeğin spor becerileri öğretimi alt boyutunun Cronbach $\alpha$ değeri .84. Yönetim ve planlama alt boyutu Cronbach $\alpha$ değeri ise .93. olarak bulunmuştur. Bu nedenle, ölçek katılımcıların güvenini ölçmek için yeterli iç tutarlılığa sahiptir ( $\alpha>$.70) (Nunnally, 1978).

Verilerin Toplanması: Veri toplama süreci 2015-2016 akademik yılı bahar döneminde gerçekleştirilmiştir. İlk olarak kendine güven ölçeğinin çalışmada kullanılabilmesi için ölçeği geliştiren araştırmacılardan gerekli izin e-posta yöntemi ile alınmıştır. Daha sonra Orta Doğu Teknik Üniversitesi Uygulamalı Etik Araştırma Merkezi İnsan Araştırmaları Etik Kurulundan etik onay izni (28620816/280-559, Haziran 2015) ve Milli Eğitim Bakanlığı’ndan çalışmanın yapılabilmesi için gerekli resmi izin (Ocak 2016) alınmıştır. Okul müdürlerine ve sınıf öğretmenlerine çalışmanın amacı hakkında bilgi verilmiştir ve sınıf öğretmenlerinden gönüllü katılım formları toplanmıştır. Ölçeğin Türkçe’ye adaptasyonundan sonra farklı sınıf öğretmenlerinden veri toplanarak çalışma tamamlanmıştır. Çalışmada kullanılan ölçeğin doldurulması yaklaşık 8-9 dakika sürmektedir.

Verilerin Analizi: Bu çalışma kapsamında doğrulayıcı ve açımlayıcı faktör analiz yöntemi, çıkarımsal istatistik yöntemlerinden MANOVA ve t-testi kullanılmıştır. İstatistiksel analizler Sosyal Bilimler için kullanılan İstatistik programı 22. sürümü (IBM SPSS 22) ve AMOS 19 programı kullanılarak gerçekleştirilmiştir.

\section{BULGULAR}

Sınıf Öğretmenlerinin Güven Seviyesi: Sınıf öğretmenlerinin beden eğitimi ve oyun dersi öğretimindeki genel güven seviyesinin orta düzeyde olduğu bulunmuştur $(X=4.00, S S=.95)$. Sınıf öğretmenlerinin yönetim ve planlama becerilerine olan güvenleri ( $X=4.24, \mathrm{SS}=.93)$, spor becerisi öğretme güven seviyesinden $(X=3.23, \mathrm{SS}=1.29)$ daha yüksek çıkmıştır (Tablo 4).

Kadın ve erkek sınıf öğretmenlerinin beden eğitimi ve oyun dersindeki güven seviyeleri arasında önemli bir fark olup olmadığını ortaya koymak için bağımsız örneklem t-testi uygulanmıştır. Elde edilen verilere göre; kadın ve erkek sınıf öğretmenlerinin beden eğitimi ve oyun dersini verirken güven seviyeleri arasında anlamlı bir fark bulunmamıştır (Tablo 4).

Tablo 4. Sınıf öğretmenlerinin beden eğitimi ve oyun dersindeki güven seviyeleri

\begin{tabular}{|c|c|c|c|c|c|c|}
\hline $\begin{array}{l}\text { Madde } \\
\text { Sayısı } \\
\end{array}$ & Ölçek Altboyutları & $\begin{array}{c}\text { Cronbach } \\
\boldsymbol{\alpha}\end{array}$ & $\mathbf{X}$ & SS & $\begin{array}{c}\text { Kadın } \\
\text { X }\end{array}$ & $\begin{array}{c}\text { Erkek } \\
\text { X }\end{array}$ \\
\hline 13 & Yönetim ve Planlama & .93 & 4.24 & .93 & 4.20 & 4.27 \\
\hline 4 & Spor Becerileri Öğretimi & .84 & 3.23 & 1.29 & 3.17 & 3.28 \\
\hline
\end{tabular}

Hizmet Yılı için MANOVA Sonuçları: Bu çalışmada kategorik bağımsız değişken (hizmet yılı) ve iki sürekli bağımlı değişken (yönetim ve planlama becerisi / spor becerisi öğretme) olduğu için tek yönlü MANOVA analizi uygulanmıştır. Tek yönlü MANOVA analizinden önce varyans homojenliği test edilmiştir. Hizmet yılı için gruplar arası 
varyans kovaryans değerleri Box’s M testi ile değerlendirilmiştir ve anlamlı bir fark bulunmamıştır (p >.05). Box’s M testi sonuçları Tablo 5.'de sunulmuştur.

Tablo 5. Box's M Test sonuçları

\begin{tabular}{ll}
\hline Box's M & 5.508 \\
\hline $\boldsymbol{F}$ & .907 \\
df1 & 6 \\
df2 & 192231.7 \\
Sig. & .489 \\
\hline
\end{tabular}

Çoklu varyans homojenliğini test etmek için Levene testi uygulanmıştır. Levene testi sonuçları yönetim ve planlama becerileri ile $(\mathrm{F}(2,317)=.485, \mathrm{p}>.05$, spor becerileri öğretme $(\mathrm{F}(2,317)=1.286 \mathrm{p}>.05)$ için anlamlı sonuçlar vermemiştir. Anlamlı olmayan sonuçlar, bu çalışma için varyans homojenliği varsayımının karşılandığını göstermiştir. Bağımsız değişkenlerin bağımlı değişkenler üzerindeki etkinliğini gösteren MANOVA sonucu, homojenlik varsayımları karşılandığı için Wilks' Lambda değeri kullanılarak yapılmıştır (Tabachnick ve Fidell, 2007). Tablo 6'da Levene's hata varyanslarının eşitliği test sonuçları verilmektedir.

Tablo 6. Levene's hata varyanslarının eşitliği test sonuçları

\begin{tabular}{llllc}
\hline & F & df1 & df2 & P \\
\hline Yönetim ve Planlama Becerileri & .485 & 2 & 317 & .616 \\
Spor Becerileri Öğretimi & .1 .29 & 2 & 317 & .278 \\
\hline $\mathrm{p}<.05$ & & &
\end{tabular}

Tek yönlü MANOVA sonuçlarına göre öğretmenlerin deneyim yılı ile kendilerine güvenleri (yönetim/planlama becerileri ve spor becerileri öğretimi) arasında anlamlı bir fark çıkmamıştır (Wilks’ Lambda =.969, F (6, 630) = 1.65, p $>$.05. Sınıf öğretmenlerinin hizmet yılı, güven değişkeni üzerindeki \% 2'lik bir farkı açıklamıştır. Hizmet yılı için MANOVA Analizi sonuçları Tablo 7'de sunulmuştur.

Tablo 7. Hizmet yılı için MANOVA sonuçları

\begin{tabular}{llllll}
\hline & $\begin{array}{c}\text { Wilks' } \\
\text { Lambda }\end{array}$ & F & Hypothesis df & Error df & Partial $\boldsymbol{\eta}^{\mathbf{2}}$ \\
\hline Hizmet Yılı & .969 & 1.65 & 6 & 630 & .02 \\
\hline
\end{tabular}

$\mathrm{p}<.05$

Okutulan Sınıf Düzeyi için MANOVA Sonuçları: Tek yönlü MANOVA analizinden önce varyans homojenliği test edilmiştir. Okutulan sınıf için gruplar arası varyans kovaryans değerleri Box’s M testi ile belirlenmiştir ve anlamlı bir fark bulunmamıştır ( $\mathrm{p}>.05$ ). Box’s M testi sonuçları aşağıdaki Tablo 8'de sunulduğu gibidir. 
Tablo 8. Box's M test sonuçları

\begin{tabular}{ll}
\hline Box's M & 9.941 \\
$\boldsymbol{F}$ & 1.092 \\
df1 & 9 \\
df2 & 761843,2 \\
Sig. & .365 \\
\hline
\end{tabular}

Çoklu varyans homojenliğini test etmek için levene's testi kullanılmıştır. Levene testi sonuçları yönetim ve planlama becerileri ile $\mathrm{F}(3,316)=1.16, \mathrm{p}>.05$, spor becerileri öğretme $\mathrm{F}(3,316)=.788$, p>.05. için anlamlı sonuçlar vermemiştir. Anlamlı olmayan sonuçlar, bu çalışma için varyans homojenliği varsayımının karşılandığını göstermiştir. MANOVA sonucu, homojenlik varsayımları karşılandığı için Wilks' Lambda değeri kullanılarak yapılmıştır (Tabachnick ve Fidell, 2007), (Tablo 9).

Tablo 9. Levene's hata varyanslarının eşitliği test sonuçları

\begin{tabular}{lllll}
\hline & F & df1 & df2 & P \\
\hline Yönetim ve Planlama Becerileri & 1.16 & 3 & 316 & .325 \\
Spor Becerileri Öğretimi & .788 & 3 & 316 & .501 \\
\hline
\end{tabular}

Tek yönlü MANOVA sonuçlarına göre öğretmenlerin okuttukları sınıf düzeyi ile kendilerine güvenleri (yönetim/planlama becerileri ve spor becerileri öğretimi) arasında anlamlı bir fark çıkmamıştır Wilks’ Lambda $=.987, F$ $(6,632)=.682, p>$.05. Sınıf öğretmenlerinin okuttukları sınıf düzeyi, güven değişkeni üzerindeki \% 0.6'lik bir fark1 açıklamıştır. Okutulan sınıf düzeyi için MANOVA analizi sonuçları aşağıdaki Tablo 10'da sunulduğu gibidir.

Tablo 10. Okutulan sınıf düzeyi için MANOVA sonuçları

\begin{tabular}{llllll}
\hline & $\begin{array}{l}\text { Wilks' } \\
\text { Lambda }\end{array}$ & F & Hypothesis df & Error df & ${\text { Partial } \boldsymbol{\eta}^{2}}$ \\
\hline Okutulan Sinıf Düzeyi & .987 & .682 & 6 & 632 & .006 \\
\hline
\end{tabular}

\section{TARTIŞMA, SONUÇ ve ÖNERILER}

Bu çalışmanın sonucunda sınıf öğretmenlerinin beden eğitimi ve oyun dersi öğretimindeki güven seviyeleri genel anlamda orta düzeyde bulunmuştur. Özellikle öğretmenlerin spor beceri öğretimi konusundaki güven seviyesi, yönetim ve planlama konusuna göre daha düşük çıkmıştır. Uluslararası düzeyde yapılan çalışmalarda da benzer sonuçlar görülmektedir. Örneğin, Morgan ve Bourke (2005) tarafından yapılan bir çalışmada, sınıf öğretmenlerinin beden eğitimi dersini işlerken temel motor becerileri öğretme konusunda kendilerine güvendikleri, ancak, cimnastik, su sporları veya atletizm gibi spor becerilerinin öğretildiği derslerde kendilerine güvenmedikleri ortaya çıkmıştır. Yapılan diğer çalışmalarda ise sınıf öğretmenlerinin beden eğitimi dersini işlerken, genel olarak kendilerine orta seviyede güvendiklerini veya az güvendikleri ortaya çıkmıştır (Morgan, 2005; Morgan ve Bourke, 2008).

Öğretmenlerin özgüvenlerinin etkileyen en önemli faktörlerin başında öğretim yeterlikleri gelmektedir (Bandura, 1986). Avrupa genelinde incelenen çalışmalarda alan uzmanı olmayan öğretmenlerin beden eğitimi dersi ile ilgili yeterliklerinin az olduğu gözlemlenmektedir (UNESCO, 2014). Bu yetersizliklerin belirlenerek giderilmesi öğretmenlerin 
özgüvenini artırarak dersin kalitesinin artırılmasına yardımcı olacağı düşünülmektedir. Öğretmenlerinin beden eğitimi ve oyun dersi gibi hareket yetkinliği içeren dersleri işleme konusunda güven veya yeterlik problemi yaşamalarının ulusal ve uluslararası düzeyde gerçekleştirilen birçok çalışmada farklı problemlerden kaynaklanabileceği savunulmaktadır. Bu problemlerin (yada bariyerlerin) başında konu ile ilgili yetersiz eğitim zaman azlığı, kalabalık sınıflar, tesis veya ekipman eksikliği gelmektedir (Faulker, Dwyer, Irwing, Allison, Adlaf ve Goodman, 2008; Morgan, 2005). Yetersiz eğitim dışında sıralanan tüm bu problemlerin kaynak eksikliğinden dolayı öğretmenler tarafından dile getirildiği ve bu konuların dersin işleyişinde problem yarattığı göz ardı edilemez. Ancak kaynak eksikliği problemlerinin dersin öğretimi konusundaki öğretmen yeterliklerini çok da etkilemediği, öğretmenlerin yaşadıkları güven sorunun konuyla ilgili yetersiz eğitimden kaynaklandığı söylenebilir.

Beden eğitimi konusunda yeterli düzeyde bilgi, beceri ve ilgiye sahip olan sınıf öğretmenlerinin bu dersi işleme konusunda özgüvenli ve başarılı oldukları görülmektedir (Petrie, 2010). Chedzoy (2000) aday sınıf öğretmenleri ile yaptığı çalışmada, etkin bir beden eğitimi dersi için a) deneyim ve bilgi birikimi, b) yeterlik ve c) ilgi ve keyif alma gibi faktörlerin önemli olduğunu ortaya koymuştur. Bu bağlamda, sınıf öğretmenlerinin beden eğitimi ve oyun dersindeki yeterliklerinin ve özgüvenlerini artırmak için konu ile ilgili bilgi ve beceri düzeylerinin artırılması gerektiği ortadadır. Bunun sağlanması için hizmet öncesi ve hizmet sonrası dönemlerde kurslar, çalıştaylar ve bunun gibi eğitim faaliyetler ile öğretmenlere ihtiyaçları doğrultusunda gerekli destek alan uzmanları tarafından verilmelidir. Ayrıca, sınıf öğretmenlerinin öğrenciler ile geçirdiği vakit daha fazla olduğundan ve verdiği farklı dersler (örn: türkçe ve matematik vb) ile beden eğitimi ve oyun dersi arasında disiplinlerarası bağı daha kolay sağlayabileceği için hareket ile ilgili dersleri verirken daha avantajlı durumda oldukları düşünülebilir.

Buna paralel olarak, sınıf öğretmenlerinin 2018 yılı öncesi lisans programları incelendiğinde, beden eğitimi ile ilgili aldıkları iki ders "beden eğitimi ve spor kültürü” ve "beden eğitimi ve oyun öğretimi " dersleridir. Sınıf öğretmenliği yeni lisans programında ise konu ile ilgili “Oyun ve Fiziki Etkinlikler Öğretimi” dersi bulunmaktadır (YÖK Sınıf Öğretmenliği Programı, 2018). Bu derslerin beden eğitimi ve oyun dersinin içerik ve işleyiş bakımından uyumlu olması ve dersi veren öğretim elemanlarının konunun uzmanı (örn. Motor gelişim uzmanı veya beden eğitimi öğretmen eğitimi uzmanı) olması önemli faktörlerdir. Lisans eğitiminde alınan bu iki dersin ve yeni programda yer alan sadece bir dersin öğretmenler için yeterli olup olmadığı tartışma konusudur. Ders sayısı azlığına çözüm olarak öğretmenlik uygulamaları (staj) sırasında beden eğitimi ve oyun dersi uygulamalarına yer verilmesi önerilmektedir. Lisans döneminde sunulan öğretmenlik uygulamaları, lisans öğrencilerinin gerçek öğretim deneyimleri yaşamasına imkân verdiğinden dolayı, bu tür fırsatların öğretmen adaylarının kendilerine güvenlerini artırdığı bilinmektedir ve yapılan araştırmalarda bunu doğrulamaktadır (Brown ve Cox, 2014).

Lisans eğitimi sonrasında da sınıf öğretmenlerine bu ders ile ilgili eğitim verilmeye devam edilmelidir. Örneğin, deneyimli beden eğitimi öğretmenlerinin sınıf öğretmenlerine destek vermesi ve hizmet içi eğitimler sırasında konu ile ilgili pedagojik bilginin beden eğitimi öğretmenleri tarafından verilmesi savunulmaktadır (Russ, 2015). Bu tür hizmet içi eğitimlerde sınıf öğretmenlerine uygulama firsatları verilmesi ve geri bildirimler doğrultusunda spor becerisi öğretimindeki alan bilgisi ve pedagojik alan bilgisinin artırılması hedeflenmelidir. Böylece öğretmenlerin ders öğretimi sırasındaki yeterliklerinin artırılması kendilerine olan güvenlerinide etkileyecek ve bu dersi işleme konusunda daha etkili olabileceklerdir (Petrie, 2010). Kısacası hizmet öncesi ve hizmet sırasında sınıf öğretmenlerine beden eğitimi ve oyun dersi ile ilgili iyi yapılandırılmış eğitim firsatları sunmak gerekmektedir.

Ders müfredatının iyi anlaşılarak doğru olarak uygulanması öğretmenlerin dersteki güven seviyesini etkileyebilecek bir başka unsur olarak düşünülmektedir. Murphy ve O’Leary (2012) tarafindan yapılan çalışmaya katılan 
sınıf öğretmenlerine beden eğitimi ve spor dersi müfredatı tanıtılmış ve öğretmenlerin dörte biri müfredatı çok daha iyi anladıklarını, ögretmenlerin yarısı da bu eğitimin müfredatı anlama konusunda yardımcı olduğunu belirtmişledir. Benzer bir şekilde beden eğitimi ve oyun dersi müfredatının doğru bir şekilde anlaşılarak uygulanabilmesi için öğretmenlere müfredatın tanıtılması, sınıf kazanımlarının açıklanması, fiziksel etkinlik kartlarının uygulama esaslarının gösterilmesi, ölçme ve değerlendirmenin örnekler ile sunulması eğitim-öğretim yıllının başında sağlanabilir. Bu şekilde öğretmenlerin dersteki güvenleri ve performansları arttırllabilir.

Başka bir öneride çevre okullarda görev yapan beden eğitimi öğretmenlerinin ihtiyaç halinde sınıf öğretmenlerine derslerde destek olmasıdır. Resmi düzenlemeler ile bu dersi çevre okullarda görev yapan beden eğitimi öğretmenleri sınıf öğretmenlerinin talebi olduğu takdirde beraber verebilmelidirler. Konusunda eğitim almış beden eğitimi öğretmenlerinin alan uzmanı olmayan öğretmenlere göre beden eğitimi dersi konusunda kendilerini daha güvenli ve yeterli hissettiklerini belirten çalışmalar mevcuttur (Burgess ve Goulding, 2009). Bu dersin en önemli boyutlarından bir olan sağlık boyutu düşünüldüğü zaman, dersin çocukların gelişimleri üzerindeki kritik bir etkisi vardır. Starc and Strel (2012) tarafindan gerçekleştirilen bir çalışmada, beden eğitimi öğretmenleri ve sınıf öğretmenlerinin çocukların fiziksel uygunluk parametrelerinde bir fark yaratıp yaratmadığı araştırılmışıır ve beden eğitimi öğretmenlerinin çocukların fiziksel uygunluklarını daha çok geliştirdikleri bulunmuştur. Bu dersin beden eğitimi öğretmenleri tarafindan verilmesi çok tartışılan bir konu olsada, beden eğitimi öğretmenlerinin desteği ile yeterli bilgi ve beceri düzeyine sahip olan sınıf öğretmenleri beden eğitimi ve oyun dersini etkili bir şekilde verebilirler.

Çalışmanın ikinci amacına yönelik çıkan sonuçlarda öğretmenlerin güven seviyelerini cinsiyet, okutulan sınıf ve hizmet yılı faktörlerinin etkilemediği görülmüştür. Bu çalışma tek bir il ve ilçede gerçekleştirilmiş̧ir. Aynı zamanda, uygulama konusunda beş yıllık gibi az bir geçmişe sahip olan beden eğitimi ve oyun dersinde, sınıf öğretmenlerin benzer deneyimler yaşamasından kaynaklı bu sonuçlar elde edilmiş olabilir. Benzer çalışmalarda farklı değişkenlerin (örn. okul türü, sınıf mevcudu veya öğrenci yaş dağılımları) sınıf öğretmenlerinin derslerde zorluk yaşamasına neden olduğu belirtilmiştir (Boz ve Yıldırım, 2014). Sınıf öğretmenlerinin geçmişteki (kendileri öğrenci iken) beden eğitimi derslerinde yaşadığı olumsuz deneyimlerin dersteki özgüven veya öz yeterliklerini etkilediği savunulmaktadır (Garrett ve Wrenh, 2007; Morgan, ve Bourke, 2008). İleride yapılacak çalışmalarda, farklı illerde eş zamanlı veriler toplanarak öğretmenlerin cinsiyet, okutulan sınıf, hizmet yıl1, okul türü veya geçmiş beden eğitimi deneyimleri gibi faktörlerin öğretmenlerin dersteki güven seviyelerine veya yeterliklerine olan etkisi araştırılabilir. Elde edilecek verilere göre öğretmen ihtiyaçları daha net bir şekilde belirlenebilir.

Sonuç olarak, bu çalışma ve benzeri çalışmalardaki bulgular göz önüne alındığı zaman, öğretmenlerin hangi alanlarda kendilerine güven duyduklarını ve kendilerini yetersiz hissetiklerinin derinlemesine araştırma yöntemleri kullanılarak ortaya çıkarılması, çözüm önerilerinin sunulması ve bu önerilerin uygulanması önem taşımaktadır. Gelecekte yapılabilecek çalışmalarda nicel veri toplama yöntemlerinin yanı sıra, nitel veri toplama araçları kullanılması öğretmenlerin bu derste yaşadıkları deneyimlerin daha gerçekçi ve bütüncül olarak ortaya konmasını sağlayacaktır (Yıldırım, 1999). Farklı branşlara yönelik spor becerileri öğretimi konusunda sınıf öğretmenlerine hizmet öncesi ve hizmet içi süreçlerde eğitim verilmesi, yönetim ve planlama konusunda öğretmenlere alan uzmanları yardımı ile destek sağlanması yararlı olacaktır. 


\section{KAYNAKLAR}

1. $\quad$ Arbuckle JL. (1999). Amos 4.0 user's guide. Measures of Fit. Chicago: Smallwaters.

2. Arslan Y, Altay F. (2008). Classroom teachers' views towards physical education curriculum and implementation of physical education. Hacettepe Journal of Sport Sciences, 19(2), 63-79.

3. Ashton P. (1984). Teachers' sense of efficacy: A self-or norm-referenced construct?. Florida Journal of Educational Research, 26(1), 2941.

4. Bandura A. (1986). The explanatory and predictive scope of self-efficacy theory. Journal of Social and Clinical Psychology, 4(3), 359-373.

5. Bayat, S., Kaymak, M. N., Balcı, O. (2016). Sınıf öğretmenlerinin oyun ve fiziki etkinlikler dersinde karşılaştıkları güçlüklere ilişkin görüşleri. Journal of Human Sciences, 13(3), 4917-4930.

6. Beaton DE, Bombardier C, Guillemin F, Ferraz MB. (2000). Guidelines for the process of cross-cultural adaptation of self-report measures. Spine, 25(24), 3186-3191.

7. Bentler PM. (1990). Comparative fit indexes in structural models. Psychological bulletin, 107(2), 238.

8. Boz T, Yıldırım A. (2014). 4+ 4+ 4 eğitim sisteminde birinci sınıf öğretmenlerinin karşılaştı̆ı̆ zorluklar. Başkent University Journal of Education, 1(2), 54-65.

9. Bozdemir R, Çimen Z, Kaya M, Demir O. (2015). Sınıf öğretmenlerinin beden eğitimi ve spor dersinde karşılaş̧ıkları problemler (Tokat ili örneği). Uluslararası Türk Eğitim Bilimleri Dergisi, 5, 221-234.

10. Brown L, Cox BJ. (2014). Exploring confidence levels of pre-service teachers in physical education field experiences. Journal of Studies in Education, 4(4), 12-19.

11. Browne MW, Cudeck R. (1993). Alternative ways of assessing model fit. Sage Focus Editions, 154, 136-136.

12. Burgess R, Goulding M. (2009). "I"m a primary non-specialist PE teacher, get me out of here." Paper presented at the British Educational Research Association Annual Conference, University of Manchester, 2-5 September 2009. http://www.leeds.ac.uk/educol/documents/184131.pdf Mart 3 adresinden erişildi.

13. Can-Ceylan G, Dalaman O. (2017). İlkokul 2. sınıf oyun ve fiziki etkinlikler dersi kazanımlarının gerçekleşme düzeyine ilişkin öğretmen görüşleri. Uluslararası Eğitm Bilimleri Dergisi, 19(4), 2345-254.

14. Chedzoy S. (2000). Students' perceived competence to teach physical education to children aged 7 to 11 years in England. European Journal of Physical Education, 5(1), 104-127.

15. Chróinín DN, O'Sullivan M. (2016). Elementary Classroom Teachers' Beliefs Across Time: Learning to Teach Physical Education. Journal of Teaching in Physical Education, 35(2), 97-106.

16. Cotton J. (2013). The Institutional Setting. Australian School of Internetional Relations (pp.7-20). Palgrave Macmillian US.

17. Dağdelen O, Kösterelioğlu İ. (2015). İlkokullardaki oyun ve fiziki etkinlikler dersinin öğretmen görüşlerine göre değerlendirilmesi. Adlyaman Üniversitesi Sosyal Bilimler Enstitüsü Dergisi, 19, 97-128.

18. Faulkner GE, Dwyer JJ, Irving H, Allison KR, Adlaf EM, Goodman J. (2008). Specialist or nonspecialist physical education teachers in Ontario elementary schools: Examining differences in opportunities for physical activity. Alberta Journal of Educational Research, 54(4), 407.

19. Hair JF, Black WC, Babin BJ, Anderson RE, Tatham RL. (2006). SEM: confirmatory factor analysis. Multivariate data analysis. Pearson Prentice Hall, Upper Saddle River, 770-842.

20. Graham JM, Guthrie AC, Thompson B. (2003). Consequences of not interpreting structure coefficients in published CFA research: A reminder. Structural Equation Modeling, 10(1), 142-153.

21. Garrett R, Wrench A. (2007) Physical experiences: primary student teachers' conceptions of sport and physical education, Physical Education and Sport Pedagogy, 12(1) pp 23-42.

22. Jones PS, Lee JW, Phillips LR, Zhang XE, Jaceldo KB (2001). An adaptation of Brislin's translation model for cross-cultural research. Nursing Research, 50(5), 300-304.

23. Jones C, Mason J. (2012) Experiential learning, Mathematics Teaching 229, pp38-41.

24. Kazu H, Aslan S. (2014). Oyun ve fiziki etkinlikler dersinin birinci sınıf öğretmenlerinin görüşlerine göre değerlendirilmesi (Elazığ ili örneği). Firat Üniversitesi Sosyal Bilimler Dergisi, 24(1), 49-63

25. Kline RB. (1998). Software review: Software programs for structural equation modeling: Amos, EQS, and LISREL. Journal of Psychoeducational Assessment, 16(4), 343-364

26. Makwana AB. (2013). The role of teacher's self confidence and teaching ability with different component of teaching. Research in Education, 2(9), 54-56. 
27. MEB. (2012). Oyun ve Fiziki Etkinlikler Dersi Öğretim Programı (1-4. sinıflar). https://tegm.meb.gov.tr/dosya/ogretimprogrami.pdf adresinden erişildi.

28. MEB. (2018). Oyun ve Fiziki Etkinlikler Dersi Öğretim Programı (İlkokul 1, 2,3 ve 4.siniflar).http://mufredat.meb.gov.tr/Dosyalar/2018120202845777OYUN\%20VE\%20FIZIKI\%20ETKINLIKLER\%20OGRETIM\%20PROGRAMI.pdf adresinden erişildi.

29. Morgan PJ. (2005). Approaches to increase physical activity: reviewing the evidence for exercise-referral schemes. Public Health, 119(5), 361-370.

30. Morgan PJ, Bourke SF. (2005). An investigation of preservice and primary school teachers' perspectives of PE teaching confidence and PE teacher education. ACHPER Healthy Lifestyles Journal,52(1), 7-13.

31. Morgan PJ, Bourke S. (2008). Non-specialist teachers' confidence to teach PE: the nature and influence of personal school experiences in PE. Physical Education and Sport Pedagogy, 13(1), 1-29.

32. Murphy F, O'Leary M. (2012). Supporting primary teachers to teach physical education: continuing the journey. Irish Educational Studies, 31(3), 297-310.

33. National Research Council. (1994). Self-confidence and Performance. Learning, Remembering. Believing: Enhancing Human Performance. Washington, DC: The National Academies Press.

34. Nunnally J. (1978). Psychometric methods. New York: McGraw-Hill

35. Pehlivan Z, Dönmez B, Yaşat H. (2005). Sınıf öğretmenlerinin beden eğitimi dersine yönelik görüşleri. Gazi Beden Eğitimi ve Spor Bilimleri Dergisi, 10, 51-62.

36. Petrie K. (2010). Creating confident, motivated teachers of physical education in primary schools. European Physical Education Review, 16(1), 47-64.

37. Russ L. (2015). The role of physical educators in helping classroom teachers to promote physical activity. Journal of Physical Education, Recreation and Dance, 86(3), 18-24.

38. Schumacker RE, Lomax RG. (1996). A beginner's guide to structural equation modeling. NJ: Lawrance Erlbaum Associates Publishers.

39. Spittle S, Watt AP, Spittle M. (2011, January). The development of a questionnaire to measure the confidence of teachers to teach primary school physical education. ACHPER 2011: Edited Proceedings of the 27th ACHPER International Conference: Moving, Learning and Achieving (pp. 248-254). ACHPER National.

40. Starc G, Strel J. (2012). Influence of the quality implementation of a physical education curriculum on the physical development and physical fitness of children. BMC Public Health, 12(1), 61.

41. Sumantri MS, Wardhani PA. (2018). The Influence of Competence and Self-Confidence on Elementary School Teacher Performance. Educational Technology to Improve Quality and Access on a Global Scale (pp. 309-320). Springer, Cham.

42. Şentürk U, Yılmaz A, Gönener U. (2015). Sınıf öğretmenlerinin oyun ve fiziki etkinlikler dersi ile ilgili görüş ve uygulamaları. Spor Yönetimi ve Bilgi Teknolojileri, 10(2), 22-30.

43. Tabachnick BG, Fidell LS. (2007). Using multivariate statistics. Allyn \& Bacon/Pearson Education.

44. Tel M, Bozkurt E, Celayir İ. (2016). İlköğretim sınıf öğretmenlerinin beden eğitimi dersine ilişkin görüşleri. Sport Sciences, 11(3), 1-10.

45. Tschannen-Moran M, Hoy AW, Hoy WK. (1998). Teacher efficacy: Its meaning and measure. Review of Educational Research, 68(2), 202-248.

46. Tucker LR, Lewis C. (1973). A reliability coefficient for maximum likelihood factor analysis. Psychometrika, 38(1), 1-10.

47. UNESCO (2014). World Wide Survey of Physical Education, Final Report 2013. http://unesdoc.unesco.org/images/0022/002293/229335e.pdf adresinden erişildi.

48. Watt H. (2000). The teaching of music in the primary school by the non-specialist, Durham theses, Durham University. Available at Durham E-Theses Online: http://etheses.dur.ac.uk/4196/.

49. Weimer M. (2012). Teaching with Confidence: Advice for New Faculty. Retrieved from 7 March 2018 https://www.facultyfocus.com/articles/teaching-professor-blog/teaching-with-confidence-advice-for-new-faculty/

50. Yıldırım A. (1999). Nitel araştırma yöntemlerinin temel özellikleri ve eğitim araştırmalarındaki yeri ve önemi. Eğitim ve Bilim, 23(112).

51. Yıldız Ö, Güven Ö. (2014). Sınıf öğretmenlerinin oyun ve fizikî etkinlikler dersinden beklentileri. Kastamonu Eğitim Dergisi, 22(2), 525538 . 